\title{
Fenton oxidation and biological treatment on pharmaceutical wastewater
}

\author{
A. Vlyssides, E. M. Barampouti, S. Mai, A. Stamatoglou \\ \& D. Skouroumounis \\ School of Chemical Engineering, \\ National Technical University of Athens, Greece
}

\begin{abstract}
Due to the wide variety of products produced in a drug manufacturing plant, pharmaceutical industry wastewater is a wastewater that is not amenable to conventional biological treatment. In this study, this wastewater was chemically pretreated using Fenton's reagent, since the initial values of the biokinetic coefficients before Fenton indicated that this wastewater could not be biologically treated. A factorial experimental procedure was designed in order to examine the influence of Fenton's pretreatment on biological oxidation. Although the Fenton oxidation process was not very effective, the overall efficiency mounted up to almost $80 \%$ in some cases. The optimum experimental conditions for the oxidation of pharmaceutical wastewater were found to be the following: $\mathrm{FeSO}_{4} \cdot 7 \mathrm{H}_{2} \mathrm{O}$ concentration $2 \mathrm{~g} \cdot \mathrm{L}^{-1}, \mathrm{H}_{2} \mathrm{O}_{2}$ concentration $2 \mathrm{~mL} \cdot \mathrm{L}^{-1}$. It was proved that after the Fenton process, the substrate was rendered significantly more biodegradable since the maximum specific uptake rate $\mathrm{K}_{\max }$ was increased from 1,76 to $3,14 \mathrm{gCOD} \cdot \mathrm{gVSS}^{-1} \cdot \mathrm{d}^{-1}$, whereas the inhibitory coefficient $\mathrm{K}_{\mathrm{s}}$ was decreased from 3752 to $732 \mathrm{mg} \cdot \mathrm{L}^{-1}$. Conclusively, Fenton oxidation could be a feasible method for the pretreatment of pharmaceutical wastewater.
\end{abstract}

Keywords: biological oxidation, factorial experiment, fenton, pharmaceutical wastewater.

\section{Introduction}

Pharmaceutical industry produces a wide variety of products. This industry uses both inorganics and organics as raw materials the latter being either of synthetic or of vegetable and animal origin [1,2]. Antibiotics and vitamins are produced by fermentation of fairly complex nutrient solutions of organic matter and inorganic 
salts by fungi or bacteria [2,3]. Synthetic drug plants utilize large number of both organic and inorganic chemicals and usually produce a variety of drugs [4]. The volume and composition of the liquid waste not only vary from plant to plant but also from section to section in a plant, producing different type of drugs from raw materials and using varieties of processes [5]. In general most of the wastes are toxic to biological life and are usually characterized by high BOD, COD and a high BOD:COD ratio $[2,6]$. Wastes from these plants are either highly alkaline or acidic [7].

Treatment of pharmaceutical wastewater has always been troublesome to reach the desired effluent standards due to the wide variety of the products produced in a drug manufacturing plant, thus, variable wastewater composition and fluctuations in pollutant concentrations. The substances synthesized in a pharmaceutical industry are structurally complex organic chemical that are resistant to biological degradation. For this reason, conventional treatment methods are usually inappropriate for the treatment of pharmaceutical wastewaters and hence there is a need for advanced oxidation methods $[8,9]$. Several different alternatives, including steam stripping, activated carbon, advanced oxidation and anaerobic treatment, were considered to be used together with aerobic biological treatment. Among these, Fenton's oxidation, an advanced oxidation method, appeared to be the most promising method, in terms of costeffectiveness and ease of operation. Recently, in a comprehensive review, Neyens \& Baeyens [10] indicated that Fenton's oxidation is very effective method in the removal of many hazardous organic pollutants from wastewaters. Fenton's oxidation can also be an effective pre-treatment step by transforming constituents to by-products that are more readily biodegradable and reducing overall toxicity to microorganisms in the downstream biological treatment processes [11]. In the present study, the applicability of Fenton's oxidation for the pre-treatment of pharmaceutical effluents originating from a large scale drug manufacturing plant was tested under laboratory conditions. The chemically treated pharmaceutical wastewater was then subjected to conventional aerobic treatment. The quantification of the influence of Fenton's reagent on the efficiency of both Fenton's oxidation and biological treatment and on the biokinetic constants was performed through a factorial experimental design [12].

\subsection{Oxidation using Fenton reactions}

As it has already been mentioned, this study uses the Fenton oxidative process. The Fenton oxidative process is a method of chemical oxidation and coagulation of organic compounds. The addition of hydrogen peroxide $\left(\mathrm{H}_{2} \mathrm{O}_{2}\right)$ and ferrous sulfate $\left(\mathrm{FeSO}_{4}\right)$ (Fenton reagent) to the waste consists the Fenton oxidative process. A theoretical approach of the Fenton oxidative processes is given below $[1,13,14]$.

Under acidic conditions, in the presence of $\mathrm{H}_{2} \mathrm{O}_{2}, \mathrm{Fe}^{2+}$ and organic substrate, the following redox reactions take place:

$$
\mathrm{Fe}^{2+}+\mathrm{H}_{2} \mathrm{O}_{2} \longrightarrow \mathrm{Fe}^{3+}+\mathrm{HO}^{-}+\mathrm{HO}^{\bullet}
$$




$$
\begin{aligned}
& \mathrm{HO}^{\bullet}+\mathrm{Fe}^{2+} \longrightarrow \mathrm{Fe}^{3+}+\mathrm{HO}^{-} \\
& \mathrm{HO}^{\bullet}+\mathrm{RH} \longrightarrow \mathrm{H}_{2} \mathrm{O}+\mathrm{R}^{\bullet} \\
& \mathrm{R}^{\bullet}+\mathrm{Fe}^{3+} \longrightarrow \mathrm{R}^{+}+\mathrm{Fe}^{2+}
\end{aligned}
$$

Reactions (1) and (2) are initiation and termination reaction, while reactions (3) and (4) are propagation reactions. The hydroxyl radicals $\mathrm{HO}^{\bullet}$ can attack and break down the organic compound $\mathrm{RH}$ or be captured by $\mathrm{Fe}^{2+}$. The radicals $\mathrm{HO}^{\bullet}$ attack the organic compounds in a minimal time and non-selectively, removing hydrogen atoms or being added to unsaturated bonds $\mathrm{C}-\mathrm{C}$. In addition, the following secondary reactions are possible:

$$
\begin{aligned}
\mathrm{HO}^{\bullet}+\mathrm{H}_{2} \mathrm{O}_{2} & \longrightarrow \mathrm{H}_{2} \mathrm{O}+\mathrm{HO}_{2}{ }^{\bullet} \\
2 \mathrm{R}^{\bullet} & \longrightarrow \mathrm{R}-\mathrm{R}
\end{aligned}
$$

Because of reaction (5), $\mathrm{H}_{2} \mathrm{O}_{2}$ captures and deactivates itself the $\mathrm{HO}^{\bullet}$ radicals and thus an increase in its concentration doesn't always lead to an increase of the efficiency of the oxidation. The ability of the Fenton reaction to decolorize the organic compounds can be attributed to the dimerization reaction $(6)[15,16]$.

But the desired reaction for the organic radicals $\left(R^{\bullet}\right)$ is not (6), but (7) below:

$$
\mathrm{R}^{\bullet}+\mathrm{O}_{2} \longrightarrow \mathrm{O}_{2} \mathrm{R}^{\bullet}
$$

The organic radicals react with the dissolved oxygen and are transformed to $\mathrm{O}_{2} \mathrm{RH}^{\bullet}$, while the lack of oxygen leads to the undesirable recombination of the organic radicals according to reaction (6) and the breaking down of the organic material is slowed down. Adding oxygen or air to the waste can considerably diminish the consumption of $\mathrm{H}_{2} \mathrm{O}_{2}$. It is desirable that the quantity of $\mathrm{Fe}^{2+}$ be as small as possible, so that reaction (2), which is using $\mathrm{HO}^{\bullet}$, is not favored.

\subsection{Biological degradation - evaluation of biokinetic constants}

The biological degradation of the organic substrate of a wastewater in an aerobic activated sludge biological system, can be expressed by the generally accepted model of Lawrence -McCarty that is another version of the Monod model.

$$
\frac{\mathrm{dS}}{\mathrm{dt}}=\frac{\mathrm{K}_{\max } \cdot \mathrm{S}}{\mathrm{K}_{\mathrm{S}}+\mathrm{S}} \cdot \mathrm{X} \quad \text { and } \quad \frac{\mathrm{dX}}{\mathrm{dt}}=\mathrm{Y} \cdot \frac{\mathrm{dS}}{\mathrm{dt}}-\mathrm{b} \cdot \mathrm{X}
$$

where: $\quad \mathrm{S}=$ biodegradable substrate concentration, $\mathrm{mg} / \mathrm{l}$

$\mathrm{X}=$ activated sludge concentration, $\mathrm{mg} / \mathrm{l}$

$\mathrm{K}_{\max }=$ maximum specific uptake rate, $\mathrm{d}^{-1}$

$\mathrm{b}=$ biomass inactivation rate, $\mathrm{d}^{-1}$

$\mathrm{Y}=$ yield coefficient

$\mathrm{K}_{\mathrm{s}}=$ substrate inhibition coefficient, $\mathrm{mg} \mathrm{L}^{-1}$

A way to estimate the course of the detoxification of a wastewater, with various treatment methods, is to monitor the empirical kinetic constants of the model mentioned above. As the wastewater gets more biodegradable, the parameter $\mathrm{k}_{\max }$ increase, while the parameter $\mathrm{K}_{\mathrm{s}}$ decrease. 
For every wastewater, the biokinetic constants of Lawrence - McCarty model differ. Nevertheless, their values are necessary for the efficient design of an aerobic treatment system.

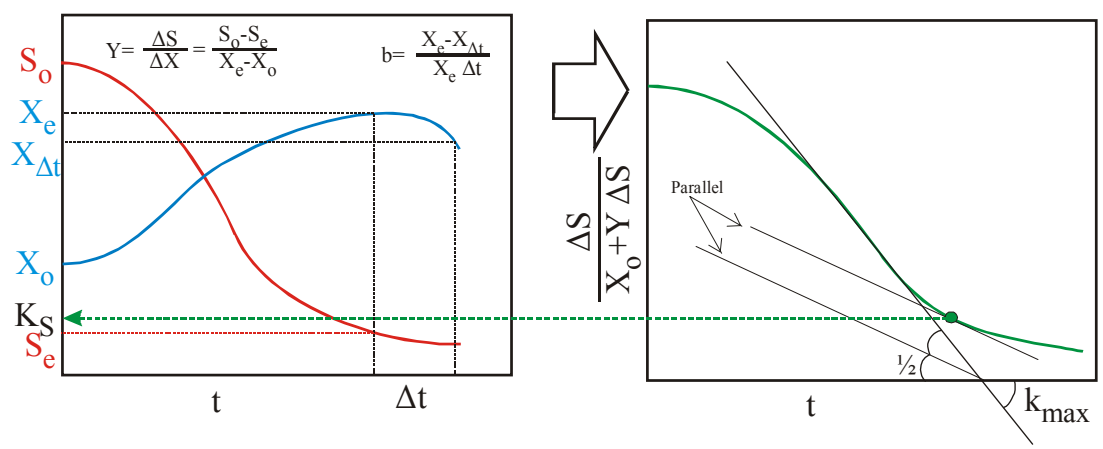

Figure 1: $\quad$ Method of evaluation of $\mathrm{Y}, \mathrm{K}_{\max }$, $\mathrm{b}$ and $\mathrm{K}_{\mathrm{s}}$ in a batch reactor.

These values can be evaluated by experiments conducted in batch reactors. In the batch reactor a certain amount of wastewater is treated aerobically and the substrate and biomass concentration is monitored. These data can be used as presented in Figure 1 in order to estimate the biokinetic constants $\mathrm{Y}, \mathrm{K}_{\max }, \mathrm{b}$ and $\mathrm{K}_{\mathrm{s}}[17,18]$.

\section{Material and methods}

\subsection{Wastewater}

The wastewater used is from a large scale drug manufacturing plant in Greece producing various products in all dosage forms such as:

- solid (plain, coated and slow-release tablets, hard gelatin caps, powders)

- semi-solid (creams, ointments, gels, suppositories)

- liquid forms (syrups, suspensions, drops, lotions)

- sterile forms (injectables/parenterals, opthalmic solutions/suspensions).

The intermittent cleaning of the tanks and filling machines used in the production processes, raw material residues, the floor cleaning as well as the wastewater coming from the quality test laboratory make up the wastewater coming out of the plant. Typically, the daily wastewater flowrate of this industrial plant amounts to about $30 \mathrm{~m}^{-1} \cdot \mathrm{d}$. The wastewater for this study was obtained from the equalization plant and characterized using standard methods [19] (Table 1).

The $\mathrm{COD} / \mathrm{BOD}_{5}$ ratio can be used to estimate the relative degradability of a waste. A low $\mathrm{COD} / \mathrm{BOD}_{5}$ ratio would indicate a large biodegradable fraction. In contrast, a waste with a high $\mathrm{COD} / \mathrm{BOD}_{5}$ ratio has a large nonbiodegradable fraction [20]. The use of the $\mathrm{COD} / \mathrm{BOD}_{5}$ ratio as an indicator of biodegradability is advantageous over the single $\mathrm{BOD}_{5}$ measurement since this ratio also takes into account the extent of the total oxidation that occurs [18]. It is acceptable that 
a waste with $\mathrm{COD} / \mathrm{BOD}_{5}$ ratio $<2$ can be easily treated by a biological system while a $\mathrm{COD} / \mathrm{BOD}_{5}$ ratio $>5$ indicates a toxic waste [20]. The $\mathrm{COD}$ :BOD ratio was estimated equal to 4,4 , thus indicating a relatively toxic waste not amenable to conventional biological treatment.

Table 1: $\quad$ Wastewater composition from a pharmaceutical industry.

\begin{tabular}{|l|l|}
\hline PARAMETER & MEAN VALUE \\
\hline $\mathrm{pH}$ & $4,3 \pm 0,3$ \\
\hline $\mathrm{BOD}_{5}\left(\mathrm{mg} \mathrm{L}^{-1}\right)$ & $1370 \pm 260$ \\
\hline $\mathrm{COD}\left(\mathrm{mg} \mathrm{L}^{-1}\right)$ & $6030 \pm 800$ \\
\hline Suspended solids $\left(\mathrm{mg} \mathrm{L}^{-1}\right)$ & $65 \pm 10$ \\
\hline Total solids $\left(\mathrm{mg} \mathrm{L}^{-1}\right)$ & $1400 \pm 400$ \\
\hline Fats and Oils $\left(\mathrm{mg} \mathrm{L}^{-1}\right)$ & $45 \pm 25$ \\
\hline Detergents $\left(\mathrm{mg} \mathrm{L}^{-1}\right)$ & $100 \pm 50$ \\
\hline Odour & Noticeable, peculiar, savoury \\
\hline Colour (dilution 1:20) & Colourless \\
\hline
\end{tabular}

\subsection{Methodology}

\subsubsection{Experimental procedure}

The wastewater from the pharmaceutical industry was initially subjected to Fenton oxidation treatment. The oxidation was carried out batchwise at $20^{\circ} \mathrm{C}$ in an agitated (100 rpm), temperature and $\mathrm{pH}$ controlled glass reactor of $1 \mathrm{~L}$ capacity for one hour. Firstly, the Fenton reagents were added. As ferrous salt, $\mathrm{FeSO}_{4} \cdot 7 \mathrm{H}_{2} \mathrm{O}$ was used and the hydrogen peroxide was of $30 \%$ concentration. Every 15 minutes, a sample was taken for analysis. After oxidation, vigorous stirring, neutralization with lime, coagulation with a weak anionic polyelectrolyte (Praestol 2540, 0,1\%) and flocculation in a jar-test apparatus, the sample was filtered and the supernatant liquid was analysed in terms of COD according to the Standard Methods for Examination of Water and Wastewater [19].

\subsubsection{Factorial design}

The aim of the experimental procedure was to determine the influence of the Fenton's reagent on the effectiveness of the oxidation and of the biological treatments in terms of \% COD removal and on the biokinetic constants. So, the parameters are heptahydrated ferrous sulphate concentration and hydrogen peroxide concentration. These parameters are referred to as "controlling parameters" of the system.

The effect of the controlling parameters on the optimization parameter was estimated by performing a $2^{2}$ factorial experiment. In general, by using a $2^{\text {n }}$ factorial design, $\mathrm{n}$ controlling parameters interrelate to an optimization parameter through an appropriate linear model. Their significance can also be estimated and assessed $[21,22]$. Then the most significant variables are altered stepwise, aiming at the determination of the optimal experimental conditions. The levels of the controlling parameters are given on Table 2. The experimental area of the factorial design was pre-determined in previous preliminary trials.

In the $2^{2}$ factorial design, 4 experiments were carried out. Four extra experiments in the center of the design (level 0) were also conducted for 
Table 2: Controlling parameters and their levels in the factorial experiment.

\begin{tabular}{|c|c|c|c|c|c|}
\hline \multirow[t]{3}{*}{ Controlling parameters } & \multirow{3}{*}{ units } & \multicolumn{4}{|c|}{ Variation intervals } \\
\hline & & As & -1 & 0 & +1 \\
\hline & & & Level & Level & Level \\
\hline $\mathrm{FeSO}_{4} \cdot 7 \mathrm{H}_{2} \mathrm{O}$ addition & $\mathrm{g} \mathrm{L}^{-1}$ & $\mathrm{X}_{1}$ & 1,0 & 1,5 & 2,0 \\
\hline $\mathrm{H}_{2} \mathrm{O}_{2}(30 \%)$ addition & $\mathrm{mL} \mathrm{L}^{-1}$ & $\mathrm{X}_{2}$ & 1,0 & 1,5 & 2,0 \\
\hline
\end{tabular}

statistical purposes. Each experiment was repeated three times and the results presented are the mean values.

From these data, mathematical models were constructed. Their adequacy was checked by the Fisher criterion. According to the latter, the following ratio should follow the F-distribution with level of importance $p=5 \%$ :

$$
F=\frac{\varsigma_{a d}^{2}}{\varsigma_{Y}^{2}}
$$

where $\varsigma_{\mathrm{Y}}^{2}$ is the standard deviation

$\varsigma^{2}$ ad is the adequacy deviation and is calculated by the following equation:

$$
S_{\text {ad }}^{2}=\frac{\sum_{i=1}^{N}\left(Y_{i}-\hat{Y}_{i}\right)^{2}}{F}
$$

where Yi: the experimental i value

$$
\hat{\mathrm{Y}}_{\mathrm{i}} \text { : the estimated } \mathrm{i} \text { value from the model determined }
$$

$\mathrm{F}$ : the number of degrees of freedom

$\mathrm{N}$ : the number of trials.

\subsubsection{Biological degradation procedure}

In a $1 \mathrm{~L}$ baker, $500 \mathrm{~mL}$ filtrate from the oxidative process were added as well as $100 \mathrm{~mL}$ of inoculant. The latter is the supernatant of a CSR bioreactor (Continuous Stirred Reactor without Sludge Recirculation), which operates with

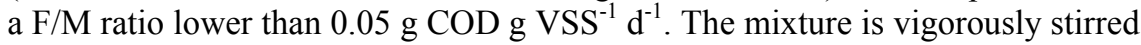
(180rpm), in order to achieve a satisfactory oxygen transfer. Every 30 minutes two $10 \mathrm{~mL}$ samples were taken, centrifuged and analyzed for COD. When COD reduction was over $70 \%$, the experiment was terminated and Total Volatile Suspended Solids were measured.

The biological degradation procedure was conducted to all chemically treated samples as well as to untreated wastewater.

\section{Results and discussion}

All samples treated had the same behaviour as far as the time function of COD reduction is concerned. In each case, a rapid COD reduction was observed the first 7 minutes and then the COD concentration remained nearly constant until the end of the experiment. In Table 3, the results of the factorial experiment 
regarding \%COD removal efficiency of the Fenton oxidation pretreatment are presented.

Table 3: \%COD removal efficiency results of the Fenton oxidation pretreatment of the factorial experiment.

\begin{tabular}{|l|l|l|l|}
\hline Trial & $\mathrm{X}_{1}$ & $\mathrm{X}_{2}$ & \%COD efficiency \\
\hline 1 & + & + & 25,56 \\
\hline 2 & - & + & 33,67 \\
\hline 3 & + & - & 30,56 \\
\hline 4 & - & - & 31,27 \\
\hline 5 & 0 & 0 & 21,78 \\
\hline
\end{tabular}

According to the results of the factorial experiment and by following a specific analytical procedure [21,22], the following model was estimated, interrelating the $\% \mathrm{COD}$ removal efficiency $\left(\mathrm{Y}_{1}\right)$ with the controlling parameters of the system:

$$
\mathrm{Y}_{1}=30,27-2,21 \mathrm{X}_{1}-0,65 \mathrm{X}_{2}-1,85 \mathrm{X}_{1} \mathrm{X}_{2}
$$

The adequacy of the mathematical model was checked by the Fisher criterion. The adequacy of the model for 5\% level of importance was:

$$
\mathrm{F}_{\text {exp }}=48,02<\mathrm{F}_{\mathrm{tab}}(5,1)=230,2
$$

where $\quad \mathrm{F}_{\mathrm{exp}}=$ the experimental value of the Fisher criterion

$\mathrm{F}_{\mathrm{tab}}=$ the value of the Fisher criterion from the statistical tables

Consequently, the model is adequate and the \%COD removal efficiency of Fenton oxidation can be expressed as:

$$
\% \mathrm{COD}_{\mathrm{r}}=30,27-2,21 \cdot \mathrm{FeSO}_{4}-0,65 \cdot \mathrm{H}_{2} \mathrm{O}_{2}-1,85 \cdot \mathrm{FeSO}_{4} \cdot \mathrm{H}_{2} \mathrm{O}_{2}
$$

In Table 4, the results of the biological oxidation experiments regarding $\%$ COD removal efficiency are presented.

Table 4: $\%$ COD removal efficiency results of the biological oxidation pretreatment.

\begin{tabular}{cccc}
\hline Trial & $\mathrm{X}_{1}$ & $\mathrm{X}_{2}$ & \%COD efficiency \\
\hline 1 & + & + & 72,68 \\
\hline 2 & - & + & 64,35 \\
\hline 3 & + & - & 63,67 \\
\hline 4 & - & - & 60,59 \\
\hline 5 & 0 & 0 & 70,77 \\
\hline
\end{tabular}

According to the results of the biological oxidation experiments, the following model was estimated, interrelating the \%COD removal efficiency $\left(\mathrm{Y}_{2}\right)$ with the controlling parameters of the system: 


$$
\mathrm{Y}_{2}=65,32+2,85 \mathrm{X}_{1}+3,19 \mathrm{X}_{2}+1,31 \mathrm{X}_{1} \mathrm{X}_{2}
$$

The adequacy of the mathematical model was checked by the Fisher criterion. The adequacy of the linear model was: $\mathrm{F}_{\exp }=19,12<\mathrm{F}_{\mathrm{tab}}=230,2$

Consequently, the model is adequate:

$$
\% \mathrm{COD}_{\mathrm{r}, \mathrm{BO}}=65,32+2,85 \cdot \mathrm{FeSO}_{4}+3,19 \cdot \mathrm{H}_{2} \mathrm{O}_{2}+1,31 \cdot \mathrm{FeSO}_{4} \cdot \mathrm{H}_{2} \mathrm{O}_{2}
$$

By use of the methodology that was presented in the theoretical section, and by assuming that the biomass concentration is nearly constant during the experiment and an equation such as the following is valid,

$$
\mathrm{COD}=(\mathrm{t}+\mathrm{C}) \cdot \mathrm{A} \cdot \mathrm{e}^{-\mathrm{B} \cdot(\mathrm{C}+\mathrm{t})}
$$

the biokinetic constants $\mathrm{K}_{\max }$ and $\mathrm{K}_{\mathrm{s}}$ were estimated for each sample (Table 5).

All the experimental results fitted best to this type of curve (eqn (15)) and that was the reason why this equation was chosen.

Table 5: $\quad$ Biokinetic parameters of biological oxidation.

\begin{tabular}{ccc}
\hline Trial & $\mathrm{K}_{\max }\left(\mathrm{g} \mathrm{COD} \mathrm{gVSS}^{-1} \mathrm{~d}^{-1}\right)$ & $\mathrm{K}_{\mathrm{s}}\left(\mathrm{mg} \mathrm{L}^{-1}\right)$ \\
\hline 1 & 2,27 & 1139 \\
\hline 2 & 3,14 & 1463 \\
\hline 3 & 2,15 & 732 \\
\hline 4 & 0,92 & 2563 \\
\hline 5 & 2,04 & 1474 \\
\hline
\end{tabular}

The sample that was not chemically treated (Trial 0) was, as it was mentioned above, subjected to biological oxidation and had an overall efficiency that equalled to $52,35 \%$. Its biokinetic constants were:

$$
\begin{gathered}
\mathrm{K}_{\max }=1,76 \mathrm{~g} \mathrm{COD} \mathrm{gVSS}^{-1} \mathrm{~d}^{-1} \\
\mathrm{~K}_{\mathrm{s}}=3752 \mathrm{mg} \mathrm{L}^{-1}
\end{gathered}
$$

Taking into consideration the estimated values of the biokinetic constants, the following models were estimated, interrelating the maximum uptake rate $\mathrm{K}_{\max }$ $\left(\mathrm{Y}_{3}\right)$ and the substrate inhibition coefficient $\mathrm{K}_{\mathrm{s}}\left(\mathrm{Y}_{4}\right)$ :

$$
\mathrm{Y}_{3}=2,12+0,09 \mathrm{X}_{1}+0,59 \mathrm{X}_{2}-0,53 \mathrm{X}_{1} \mathrm{X}_{2}
$$

The adequacy of the model was: $F_{\text {exp }}=13,12<F_{\text {tab }}=230,2$

Consequently, the model is adequate:

$$
\begin{gathered}
\mathrm{K}_{\max }=2,12+0,09 \cdot \mathrm{FeSO}_{4}+0,59 \cdot \mathrm{H}_{2} \mathrm{O}_{2}-0,53 \cdot \mathrm{FeSO}_{4} \cdot \mathrm{H}_{2} \mathrm{O}_{2} \\
\mathrm{Y}_{4}=1474,41-538,71 \mathrm{X}_{1}-173,40 \mathrm{X}_{2}+376,90 \mathrm{X}_{1} \mathrm{X}_{2}
\end{gathered}
$$

The adequacy of the model was: $\mathrm{F}_{\exp }=11876>\mathrm{F}_{\mathrm{tab}}=230,2$

Consequently, this model can not be used for the substrate inhibition coefficient $\left(\mathrm{K}_{\mathrm{s}}\right)$ prediction. 


\section{Conclusions}

In order to draw the main conclusions of this study, the overall efficiencies of the pharmaceutical wastewater treatment are presented in Table 6.

Table 6: Overall \%COD removal efficiency results.

\begin{tabular}{cccc}
\hline Trial & $\mathrm{X}_{1}$ & $\mathrm{X}_{2}$ & \%COD efficiency \\
\hline 0 & & & 52,35 \\
\hline 1 & + & + & 79,90 \\
\hline 2 & - & + & 79,96 \\
\hline 3 & + & - & 75,43 \\
\hline 4 & - & - & 72,92 \\
\hline 5 & 0 & 0 & 77,16 \\
\hline
\end{tabular}

Treatment with Fenton's oxidation improved the biodegradability and reduced the toxicity of the pharmaceutical wastewater. Fenton oxidation was an effective pre-treatment method for the non-biodegradable portions of the pharmaceutical wastewater, which rendered them more biodegradable for following biological processes. In all cases, the overall efficiency mounted over $70 \%$, significantly higher than the untreated sample. $\mathrm{K}_{\max }$ was substantially increased while Ks decreased, indicating a more efficient biological treatment. The optimum results were obtained in Trial 2 for $2 \mathrm{~g} \mathrm{~L}^{-1} \mathrm{FeSO}_{4}$ and $2 \mathrm{~mL} \mathrm{~L}^{-1}$ $\mathrm{H}_{2} \mathrm{O}_{2}$. From eqns (14) and (17), it is obvious that by increasing the dosage of chemicals not only the efficiency of biological treatment increases but also the maximum specific uptake rate. This implies that the Fenton oxidation pretreatment improves the biodegradability of the pharmaceutical wastewater.

\section{References}

[1] Eckenfelder, W.W.J, Industrial water pollution control, McGraw-Hill Book Company: New York, 1989

[2] Rao, M.N., Datta, A.K., Wastewater treatment, Oxford/IBH Publishing Co.: New Delhi, 1987.

[3] De, A.K., Environmental chemistry, Wiley Eastern Limited/Newage International Limited: New Delhi, 1996.

[4] Mohan, S.V., Prakasham, R.S., Satyavathi, B., Annapurna, J., Ramakrishna, S.V., Biotreatability studies of pharmaceutical wastewaters using anaerobic suspended film contact reactor. Water Science \& Technology, 43(2), 271-276, 2001.

[5] Davis, M.L., Cornwell, D.A., Introduction to environmental engineering, McGraw-Hill International Edition: New York, 1998.

[6] Bethatech, D.A., Choose appropriate wastewater treatment technologies. Chemical Engineering Progress, 12, 32-51, 1995. 
[7] Suman Raj, D.S., Anjaneyulu, Y., Evaluation of biokinetic parameters for pharmaceutical wastewaters using aerobic oxidation integrated with chemical treatment. Process Biochemistry, 40, 165-175, (2005).

[8] Balcioglu, I.A., Otker, M., Treatment of pharmaceutical wastewater containing antibiotics by $\mathrm{O}_{3}$ and $\mathrm{O}_{3} / \mathrm{H}_{2} \mathrm{O}_{2}$ processes. Chemosphere, 50, 8595, 2003.

[9] Cokgor, U.E., Alaton, I.A., Karahan, O., Dogruel, S., Orhon, D. Biological treatability of raw and ozonated penicillin formulation effluent. Journal of Hazardous Materials, 116, 159-166, 2004.

[10] Neyens, E., Baeyens, J. A review of classic Fenton's peroxidation as an advanced oxidation technique. Journal of Hazardous Materials, 98, 33-50, 2003.

[11] Miller, C.M., Valentine, R.L., Roehl, M.E., Alvarez, P.J.J. Chemical and microbiological assessment of pendimethalin-contaminated soil after treatment with Fenton's reagent. Water Research, 30, 2579-2586, 1996.

[12] Tekin, H., Bilkay, O., Ataberk, S., Balta, T., Ceribasi, H., Sanin, D., Dilek, F., Yetis, U. Use of Fenton oxidation to improve the biodegradability of a pharmaceutical wastewater. Journal of Hazardous Materials, B136, 258-265, 2006.

[13] Metcalf and Eddy, Wastewater Engineering - Treatment, Disposal \& Reuse, McGraw- Hill: New York, 1991.

[14] Vlyssides, A., Loukakis, C., Israilides, C., Barampouti, E.M., Mai, S. Detoxification of olive mill wastewater using a fenton process. Proc. of the $2^{\text {nd }}$ European Bioremediation Conference, Chania, Greece, 531-535, 2003.

[15] Lin, S., Lo, C. Fenton process for treatment of desizing wastewater. Water Research, 31(8), 2050-2056, 1997.

[16] Prousek, J., Fenton reaction after a century. Chemicke Listy, 89, 11-21, 1995.

[17] Giona, A., Annessini, M., Kinetic parameters for municipal wastewater. Water Pollution Control Federation, 51(5), 999-1008, 1979.

[18] Thomas, A.H., Graphical determination of BOD curves constants. Water Sewage Works, 97, 123-128, 1950.

[19] APHA-AWWA-WPCF. Standard Methods for the Examination of Water and Wastewater, APHA: Boston, 1989.

[20] Simond, O., Shaller, V., Comninellis, C., Theoretical model for the anodic oxidation of organics on metal oxide electrodes. Electrochimicka Acta, 42(13/14), 2009-2012, 1997.

[21] Alder, Y., Markova, E., Granovsky, Y., The design of experiments to find optimal conditions, Mir Publishers: Moscow, 1995.

[22] Cochran, W., Cox, G., Experimental designs, John Wiley \& Sons Inc.: New York, 1957. 